\title{
The Effects of the Synchronous Discussion and Reflection System (SDRS) In Perception of Knowledge Building and Learning Outcomes
}

\author{
Cinthya Indrastyawati \\ National Central University, Taiwan and Universitas Negeri Yogyakarta, Indonesia, \\ cinthya.indrastya@gmail.com
}

\section{Ying-Tien Wu}

National Central University, Taiwan, ytwu@cl.ncu.edu.tw

\section{Sugito}

Universitas Negeri Yogyakarta, Indonesia, sugito@uny.ac.id

The purposes of this study are to understand the effects of using Synchronous Discussion and Reflection System (SDRS) platform in the elementary students' perception of the learning environment and students' cognitive outcomes regarding the Genetically Modified Food (GMF). A total of 22 students from Elementary School in Taichung Taiwan joined this study, consisted of 10 students in the experimental group and 12 students in the control group. The results of the study showed: (1) The experimental group using SDRS have advantages in self-directed discussion and reflection than the control group by teacher guidance; (2) students' perception in the KB-Based learning environment from the experimental group is as good as the control group; (3) learning outcomes in the experimental group are better than the control group. So this study concludes that the Knowledge Building-Based Learning using SDRS as a platform for self-directed discussion and reflection was equally more effective than with using the discussion guide by the teacher in class. This study also suggests that elementary school students need more time to adapt using the platform in KB-based learning to get better result both in their perception of the learning environment and their learning outcomes.

Keywords: knowledge building, learning environment, learning outcomes, reflection, students perception

\section{INTRODUCTION}

Learning is a process between students and educators where students achieve all the knowledge and skill for the learning objectives. In traditional way learning objectives are often considered complete only when a student can produce the correct answer to a

Citation: Indrastyawati, C., Wu, Y-T., \& Sugito. (2020). The Effects of the Synchronous Discussion and Reflection System (SDRS) In Perception of Knowledge Building and Learning Outcomes. International Journal of Instruction, 13(3), 699-710. https://doi.org/10.29333/iji.2020.13347a 
question that the teacher gave (Karpicke \& Roediger, 2008). The success of a learning process only depended into the final results without considering the learning process. In fact, the achievement of the competency must be evaluated continuously and need teachers' assessment in the process (Scallon, 2007). The traditional way of learning proven cannot effectively make student engage in their study, because information only comes from the teacher as the teacher instills knowledge directly to the student. Student gets the information only from the teacher, as we know the teacher-centered learning methods. The teacher would become the primary responsibility for the communication of knowledge to students and had a role as the source of all information (Mascolo, 2009). This method will make students passively learning, receptive mode listening as the teacher teaches without considered student fully understanding while in the learning process.

To improve the quality of learning, it's not only talking about how a teacher can teach well but also how students can learn well. Student-centered learning comes from the quest so that all students have good performance in their educational goals (Ireri, et al., 2017). Student-centered learning source from the constructivism theory, which in that theory students learn by connecting new knowledge with their prior knowledge and concepts, and constructing their new understanding. Learners build knowledge as they explore the world around them, observe and interact with the phenomena, also communicate and engage with others. (DeVries, \& Kohlberg, 1997; Fosnot \& Perry, 2005; Kolb, 1984; Piaget, 1948/1973 in Mascolo, 2009).

Knowledge building is a process where knowledge is purposely developed and students need to work collaboratively to solve, discuss, and compare common problems and express their ideas. The achievement of the community will be greater than the total of individual contributions and part of more extensive cultural efforts (Bereiter \& Scardamalia, 2003; 2006). In knowledge building, we talk about idea-centered collaboration which sharing ideas in a community and have the common interest and certain goals (Hong \& Lin, 2019). This collaborative learning makes the student more engaged in their learning because as the individuals they need to share their ideas as a group member and also discuss it. This process would interactively accomplish the community construction and maintenance of shared conceptions of tasks, so collaborative learning has more meaning than only involves individual learning (Stahl, Koschmann, \& Suthers, 2006). As we can see the knowledge building paid attention more to the importance of the learning process in the student rather than the final result only. The science learning collaboration encourages the sharing and contrasting of ideas within other individuals within a community who are engaged in similar tasks and purposes. Finally, inquiry, that plays a foundational role within science, requires the students to engage in problem-stating and problem-solving activities which require planning, synthesis, and evaluation skills, as well as, relevant domain-specific content knowledge (Mayer, 2011).

Computer-Supported Collaborative Learning (CSCL) is an instructional method that makes collaboration learning interaction process happen with the help of computers or through the internet. The sharing and construction of knowledge among participants 
would be using technology as their main means of a communication or as a shared resource (Stahl et al., 2006). The main purpose of CSCL environments is to support sharing in the knowledge building process that is realized by the learners in developing knowledge society qualifications (Scardamalia \& Bereiter, 2006; Stahl et al., 2006; Yücel \& Usluel, 2016). Students in the collaborative learning supported by technology would enhance the effectiveness of knowledge building learning environments, like facilitate sharing and distributing knowledge and expertise among the community members (Lipponen, 2010). In Taiwan, application of Computer-Supported Collaborative learning is widely supported in the school. There were several research regarding the application of CSCL in Taiwan for example based on research by $\mathrm{Wu} \&$ Tsai (2007; 2010), and Wu (2012) using CSCL system for determine the students' knowledge structures and informal reasoning in socio-scientific issue. Another example from based on the research by Hou \& Wu (2011) using CSCL in online synchronous Instant Messaging (IM) tools to analyze student social knowledge construction.

Traditional learning methods cannot effectively make student engage in their study, so this study aims to improve the students learning by using technology (computersupported collaborative learning/CSCL) that is Synchronous Discussion and Reflection System (SDRS) to support the student to reflect their previous discussion and make students got more understanding in their learning. The reflection in the learning process is important because it would help the student to reflect in their previous result and make a clarification in themselves that lead to better perspectives (Boyd \& Fales, 1983; Brockbank \& McGill, 2006). Students should be able to review the knowledge they have before (prior knowledge) and then connect with new information that will be obtained in their learning (P. L. Smith \& Ragan, 2005). The function of Synchronous Discussion and Reflection System (SDRS) in knowledge building learning is facilitating student discussion and help students reflects from the discussion. In this system, there is a record feature that can help students repeat or listen to the discussions they have done before. This system accessed via online and can connect the student within group in same time (synchronous).

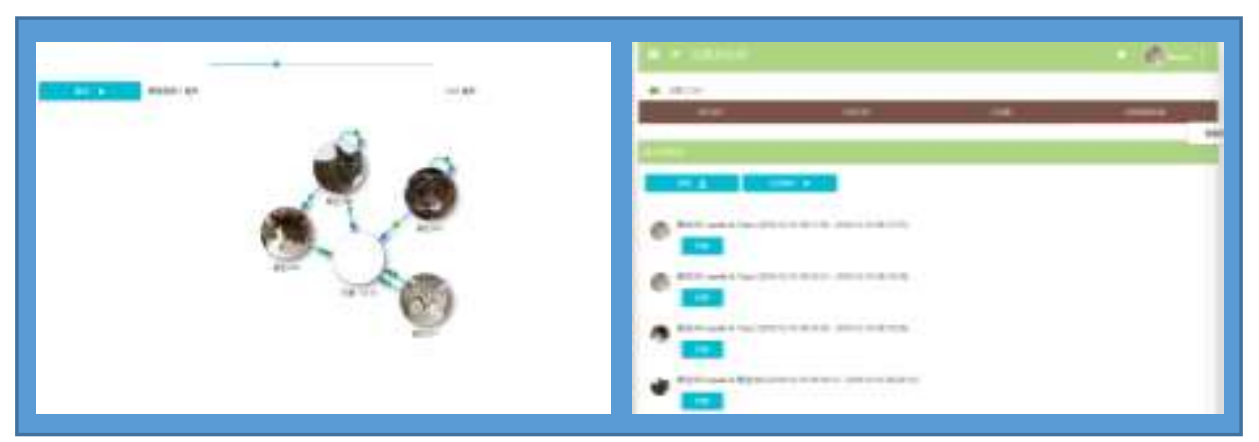

Figure 1

Discussion Map \& Speech Recording Screen in Synchronous Discussion and Reflection System (SDRS) 
This study focused on applying Knowledge Building-Based Learning in the classroom by using the SDRS platform for the experimental group and traditional way with teacher guidance in the student discussion process. The results that analyze in this study were students' perception about the Knowledge Building-based learning environment and the group discussion results outcomes. The aims of this study following the research questions, there are:

1. What is the students' perception regarding the knowledge building-based learning environment?

2. What is the students' discussion learning outcomes from the knowledge buildingbased learning?

\section{METHOD}

\section{Participants}

Research participants in this study were 22 students from Ching-Sui Elementary School in Taichung Taiwan, consisted of 10 students as experimental group and 12 students as the control group. Both of group used Knowledge Building-Based Learning. The experimental group was given the Synchronous Discussion and Reflection System (SDRS) to help in their reflection in the group discussion and the control group guided by the teacher in their discussion.

\section{Research Design and Procedure}

This study used quasi-experimental research to measure the effect of SDRS in students' perception of Knowledge Building-Based Learning Environment and Learning Outcomes. The quasi-experimental research purpose is to test descriptive causal hypotheses that causes-as well as many structural details to support a counterfactual inference if there is no treatment (Shadish, Cook, \& Campbell, 2002).

The duration of this study conducted for 4 weeks with 2 hours' class per week. The main topic used for discussion is Genetically Modified Food with different subject matter every week. During the class, the teacher divided the students into small groups and provides articles and internet access for the student to looking for information while discuss and share their ideas within groups. The experimental group did self-directed learning because it uses SDRS in their discussions and reflection while the control group needs the teacher's guide in their discussion because they did not use any platform to support their discussion. From every week discussion, every group of student would obtain and report their discussion results about every week topic. This students group discussion results would analyze as the Knowledge Building-Based learning outcomes. Also before and after this research conducted, students would be given the knowledge building environment scale questionnaire to measure their perception about knowledge building-based learning. 




Figure 2

The Research Design and Procedure

\section{Data Collection and Data Analysis}

Student perception of KB-based environment was collected and measured by a KBES questionnaire that adapted from Lin, Hong, \& Chai (2014) based on the knowledge building pedagogy. The questionnaire identified three factors as a core dimension of the knowledge building environment, there were working with the idea (WI), assuming agency (AA), and fostering community (FC). The KBES uses a four-point Likert scale, ranging from 1 (strongly disagree) to 4 (strongly agree).

Table 1

The Sample Items of factors in KBES Questionnaire

\begin{tabular}{ll}
\hline \multicolumn{1}{c}{ Factors } & \multicolumn{1}{c}{ Sample items } \\
\hline Working with Idea (WI) & In this course, all ideas in the class were worthy of consideration \\
\hline Assuming Agency (AA) & $\begin{array}{l}\text { In this course, one needed to plan and execute one's learning } \\
\text { plan. }\end{array}$ \\
\hline $\begin{array}{l}\text { Fostering Community } \\
\text { (FC) }\end{array}$ & $\begin{array}{l}\text { In this course, the participation of all members in the community } \\
\text { is important. }\end{array}$ \\
\hline
\end{tabular}

These core dimensions could have reflected the learning process creative extent of the knowledge building environment in the classrooms. There were two Knowledge Building Environment Scale questionnaire that given to the student to measuring the student perception. The first questionnaire was given before the course started (pre-test) to measure their prior information about their past learning experience. The second questionnaire was given to the student after the study conducted as a post-test. The second Knowledge Building Environment Scale Questionnaire was to measure the student perception in their knowledge building-based learning environment.

The student learning outcomes would have collected from each week group discussion and analyzed with qualitative analysis. Students' discussion results were categorized based on their answer on each week. From the categorized keywords of their discussion 
results, the researcher could analyze by observe their amounts of results and new category that appear in their group discussion results on each week. The amounts and category that appear in the discussion results from the experimental and control group per week would measure the students understanding and their knowledge construction about the Genetically Modified Food (GMF) in the Knowledge Building-Based Learning.

\section{FINDINGS}

\section{Student Perception of Knowledge Building-Based Learning Environment.}

The student perception of Knowledge Building-Based Learning Environment results conducted with ANCOVA to find out the difference between the students' perception from the two groups. As shown in table 2, the result from $F$ value is 0.06 , higher than 0.05 (F, p >0.05) it's mean the result is not significant or there is no significant difference between experimental group and control group. So we can conclude that there are no differences between the two groups so the knowledge building-based learning environment in the experimental group is as good as the in the control group.

Table 2

The ANCOVA result of Student Knowledge Building Environment Perception

\begin{tabular}{lllll}
\hline & & Mean (adjusted) & Std. Error & \multirow{2}{*}{ F-value } \\
\hline Working & Experimental Group $(\mathrm{n}=10)$ & 3.24 & 0.32 & \multirow{2}{*}{0.32 (n.s.) } \\
\cline { 2 - 5 } with Ideas & Control Group $(\mathrm{n}=12)$ & 3.27 & 0.31 & \\
\hline \multirow{2}{*}{$\begin{array}{l}\text { Assuming } \\
\text { Agency }\end{array}$} & Experimental Group $(\mathrm{n}=10)$ & 3.04 & 0.41 & \multirow{2}{*}{0.01 (n.s.) } \\
\cline { 2 - 5 } $\begin{array}{l}\text { Fostering } \\
\text { Community }\end{array}$ & Experimental Group $(\mathrm{n}=10)$ & 3.54 & 0.35 & \\
\cline { 2 - 5 } Tontrol Group $(\mathrm{n}=12)$ & Control & 3.53 & 0.44 & (n.s.) \\
\hline \multirow{2}{*}{ Total } & Experimental Group $(\mathrm{n}=10)$ & 3.43 & 0.43 & \multirow{2}{*}{0.06 (n.s.) } \\
\cline { 2 - 5 } & Control Group $(\mathrm{n}=12)$ & 3.44 & 0.34 & \\
\hline
\end{tabular}

\section{Student Knowledge Building-Based Learning Outcomes}

The student KB-based learning outcomes analyze with qualitative analysis. Each group per week answer categorize in some main theme. From the analysis, there are 11 categories that researcher found from the keyword of the results from all students' groups discussion. The categories were: (1) benefit of GMF, (2) definition of GMF, (3) disadvantages of GMF, (4) ecological impact, (5) GMF example, (6) health impact, (7) impact on animal, (8) impact on plant, (9) national regulation of GMF, (10) person related to GMF, and (11) specifications of GMF. The analysis conducted would measure the student understanding about the topic and their knowledge construction in the Knowledge Building-Based Learning.

The result of the analysis in table 3 and Table 4 shows that in the first week, the experimental group gets 7 different categories in the outcomes of their results while the control group only 6 categories. But in their learning outcomes results, the control group got 20 outcomes while the experimental group got 16 outcomes. Then in the second week, both group amount categories are 6 and some of the category different from the 
first week. It means that there was some knowledge construction process in the student discussion because there was some new category that appears different from the last week result. The result outcomes in the experimental group got big different result in their discussion compare with the control group, there were 26 outcomes while the control group were 16 outcomes.

On the third week, we can see big differences between experimental and control group. The experimental group got the new keyword in their group discussion and more amount of keyword ( 6 categories) so as we can see that the knowledge construction better than in the control group ( 2 categories). For the results outcomes, the experimental group (20 outcomes) get higher results than the control group (15 outcomes). For the last week, students on both experimental and control group discussion result outcomes were mostly concluded from their discussion in the past weeks (The experimental group 6 categories and the control group 5 categories) with the new addition of their knowledge about GMF. So from the analysis, we could see that from both of the group there was a knowledge construction in the students, as among week they have advanced their understanding. The results outcomes also got almost similar result amounts between two groups, as the control group slightly higher (17 outcomes) than the experimental group (15 outcomes). Overall, the experimental group got better results outcomes from the control group based on the result amounts in each week and also in the total result amounts. Total amounts from the experimental group of different keyword categories were 11 categories and the outcomes amounts were 77 outcomes while the control group were 9 categories and learning outcomes were 68 outcomes.

Table 3

The Amount of Keyword Categories

\begin{tabular}{|c|c|c|c|c|}
\hline \multirow{2}{*}{ Week } & \multicolumn{2}{|c|}{ Experimental Group } & \multicolumn{2}{|c|}{ Control Group } \\
\hline & Amount & Keyword Categories & Amount & Keyword Categories \\
\hline $1^{\text {st }}$ & 7 & $\begin{array}{l}\text { Specification, Disadvantages, } \\
\text { Health, Ecological, Example, } \\
\text { Definition, Person }\end{array}$ & 6 & $\begin{array}{l}\text { Definition, Health, Example, } \\
\text { Benefit, Ecological, National } \\
\text { Regulation }\end{array}$ \\
\hline $2^{\text {nd }}$ & 6 & $\begin{array}{l}\text { Impact on Plant, Benefit, Health, } \\
\text { Impact on Animal, } \\
\text { Disadvantages, Ecological }\end{array}$ & 6 & $\begin{array}{l}\text { Impact on Plant, Benefit, } \\
\text { Disadvantages, Ecological, } \\
\text { Health, Impact on Animal }\end{array}$ \\
\hline $3^{\text {rd }}$ & 7 & $\begin{array}{l}\text { National Regulation, } \\
\text { Disadvantages, Health, Impact on } \\
\text { Animal, Impact on Plant, } \\
\text { Example, Benefit }\end{array}$ & 2 & Example, National Regulation \\
\hline $4^{\text {th }}$ & 6 & $\begin{array}{l}\text { Ecological, Disadvantages, } \\
\text { Health, Impact on Plant, Impact } \\
\text { on Animal, Benefit }\end{array}$ & 5 & $\begin{array}{l}\text { Disadvantages, Health, Impact } \\
\text { on Plant, Impact on Animal, } \\
\text { Benefit }\end{array}$ \\
\hline $\begin{array}{l}\text { Total } \\
\text { Amount } \\
\text { of } \\
\text { Categories }\end{array}$ & 11 & $\begin{array}{l}\text { Specification, Disadvantages, } \\
\text { Health, Ecological, Example, } \\
\text { Definition, Person, Impact on } \\
\text { Plant, Impact on Animal, Benefit, } \\
\text { National Regulation }\end{array}$ & 9 & $\begin{array}{l}\text { Definition, Example, Benefit, } \\
\text { Health, Ecological, Impact on } \\
\text { Animal, National Regulation, } \\
\text { Disadvantages, } \\
\text { Impact on Plant }\end{array}$ \\
\hline
\end{tabular}




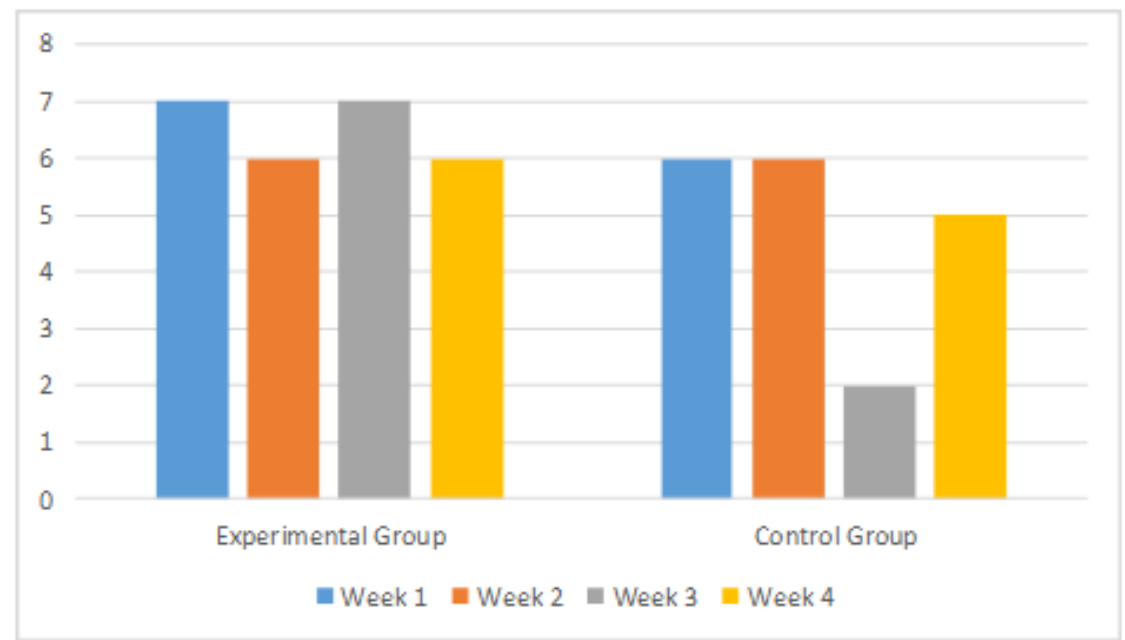

Figure 2

The Amount of Categories each Week between Experimental and Control Group

Table 4

The Amount of Result Categories and Learning Outcomes

\begin{tabular}{|c|c|c|c|c|}
\hline \multirow{2}{*}{ Week } & \multicolumn{2}{|c|}{ Experimental Group } & \multicolumn{2}{|c|}{ Control Group } \\
\hline & N Categories & N Outcomes & N Categories & N Outcomes \\
\hline $1^{\mathrm{st}}$ & 7 & 16 & 6 & 20 \\
\hline $2^{\text {nd }}$ & 6 & 26 & 6 & 16 \\
\hline $3^{\text {rd }}$ & 7 & 20 & 2 & 15 \\
\hline $4^{\text {th }}$ & 6 & 15 & 5 & 17 \\
\hline Total & 11 & 77 & 9 & 68 \\
\hline \multicolumn{5}{|l|}{30} \\
\hline \multicolumn{5}{|l|}{25} \\
\hline \multicolumn{3}{|l|}{20} & & \\
\hline \multicolumn{5}{|l|}{15} \\
\hline \multicolumn{5}{|l|}{10} \\
\hline \multicolumn{5}{|l|}{5} \\
\hline \multicolumn{5}{|c|}{ alGroup } \\
\hline & & ek 1 Week 2 & eek 3 week & \\
\hline
\end{tabular}

Figure 3

The Amount of Learning Outcomes Result in each Week between Experimental and Control Group 


\section{DISCUSSION}

From the findings, student perceptions of KB-based learning environment in the experimental group are as good as in the control group because there is no significant difference in the results $(\mathrm{F}=0.06)$. There were some possibilities that affects this result. First, based on the definition from Bereiter \& Scardamalia $(2003 ; 2006)$ the knowledge building is defined as a group activity where knowledge is intentionally developed and students collaboratively work to solve, discuss, and compare common problems and express their ideas. The main factor of this activity is interaction. Although each group, experimental or control group, has different structure of interaction, we assume that the students still have an opportunity to interact with their peer. It promoted interdependence. Deutsch (2012) stated that when the group members have positive interdependence, they coordinate their efforts, communicate effectively and share similar beliefs and values with other group members. Second, the participants are the elementary school students that need a teacher to guide them more than higher level school students. Based on Piaget (1936) theory of cognitive development, elementary students (children age between 7-11 years old), they can only solve problems that apply to concrete events or objects (Ginsburg \& Opper, 2002). Elementary students need more time to construct their knowledge in knowledge building-based learning environment, especially for the experimental group with self-directed learning that less teacher guidance than the control group.

In the learning outcomes, the experimental group got better results than the control group based on the result amounts in each week and also in the total result amounts. The experimental group total amounts of different keyword categories were 11 categories and the outcomes amounts were 77 outcomes while the control group were 9 categories and learning outcomes were 68 outcomes. This finding in line with Choi, J. \& Walters' work (2018) that student who participated in more small-group synchronous discourse sessions had both higher final course scores and higher odds of scoring at or above Proficient on the state assessments in math. The experimental group results in accordance with the purpose of reflection in learning based from the Rodgers (2002) that reflection in student learning could make more meaning from one experience to the next experience with a deeper understanding of their relationship with and connection to other experiences and ideas. In the experimental group, we could say that the student effectively uses the platform for reflection in their discussion because the results outcomes in each week are better than the control group. The experimental group students learn from their past week results and got a better result in the next week because of the help of SDRS platform for their reflection.

The experimental group that given the SDRS platform for self-directed learning comparing with the control class with teacher mostly directed the class, their result is almost similar in both of perception of knowledge building-based learning and group discussion learning outcomes. So in the big picture, the Knowledge Building-Based Learning using application of SDRS as a platform for self-directed learning in discussion and reflection was equally effective with the discussion by the teacher guidance in the class. 
To understand more about the cause of the results, we added some interview to 3 students in the experimental group. There was some addition to future research that we get from the interview. Overall, the students feel positive about the usage of the Synchronous Discussion and Reflection System (SDRS) platform. The students said the platform is interesting to use individually and collaboratively, as they get new information about the topics. This finding is consistent with prior work that synchronous cyber classroom outperforms all other modes of instruction in enabling students to simultaneously integrate visual, auditory and kinaesthetic processes, provides learners with more authentic and engaging learning activities (Hastie, Chen, \& Kuo, 2007). There were some suggestions from the student about the platform, like fix the crash in the system, need more time to adapt with the platform (the research conducted for 8 hours in 4 weeks) and add some game to make more interesting in learning. For future suggestion, the elementary school students need more time to adapt using the platform in knowledge building-based learning to get better result both in their perception of the learning environment and their learning outcomes.

\section{CONCLUSION AND SUGGESTION}

This study aims to understand the students' perception of the learning environment and students learning outcomes by applying Knowledge Building-Based Learning in the classroom. The result in the student perceptions of KB-based learning environment shows that the experimental group is as good as in the control group. The students' discussion learning outcomes results shows that the experimental group is better than the control group. The knowledge construction is better in the experimental group with the help of the Synchronous Discussion and Reflection System (SDRS) than the control group by the teacher guidance. So this study concludes that the Knowledge BuildingBased Learning using SDRS as a platform for self-directed discussion and reflection was equally effective with the discussion guide by the teacher in class.

There are some suggestions for the better results in both the perception of the learning environment and learning outcomes using Synchronous Discussion and Reflection System (SDRS). The amounts of time study conducted need more addition for the better result using the platform. This study considered a success even though there is some part that does not meet the expectations. For the future study, the Synchronous Discussion and Reflection System (SDRS) in the knowledge building-based learning can explore more in another learning activity and another level of the student not only in the elementary school but also in the higher level student.

\section{REFERENCES}

Bereiter, C., \& Scardamalia, M. (2003). Learning to work creatively with knowledge. EARLI advances in learning and instruction series. In E. De Corte, L. Verschaffel, N. Entwistle, \& J. van Merriënboer (Eds.), Powerful learning environments: Unravelling basic components and dimensions (p. 239). Emerald Group Publishing Limited.

Boyd, E. M., \& Fales, A. W. (1983). Reflective learning. Journal of Humanistic Psychology, 23(2), 99-117. 
Brockbank, A., \& McGill, I. (2006). Facilitating reflective learning through mentoring and coaching. Retrieved from https://epdf.tips/facilitating-reflective-learning-throughmentoring-amp-coaching.html.

Choi, J., \& Walters, A. (2018). Exploring the impact of small-group synchronous discourse sessions in online math learning. Online Learning, 22(4), 47-64

Deutsch, M. (2012). A theory of cooperation: Competition and beyond. In P. A. M. Van Lange, A. W. Kruglanski, \& E. T. Higgins (Eds.), Handbook of theories of social psychology: Volume 2 (pp. 275-294). London: Sage Publications

Ginsburg, H. P., \& Opper, S. (2002). Piaget's theory of intellectual development. Journal of School Psychology, 19(1), 94.

Hastie, M., Chen, N.-S., \& Kuo, Y.-H. (2007). Instructional design for best practice in the synchronous cyber classroom. Educational Technology \& Society, 10(4), 281-294

Hong, H.-Y., \& Lin, P.-Y. (2019). Elementary students enhancing their understanding of energy-saving through idea-centered collaborative knowledge-building scaffolds and activities. Educational Technology Research and Development, 67(1), 63-83.

Ireri, B. N., Omwenga, E. I., Oboko, R., \& Wario, R. (2017). Developing pedagogical skills for teachers: A learner-centered approach for technology supported instructions. In J. Keengwe \& G. Onchwari (Eds.), Handbook of research on learner-centered pedagogy in teacher education and professional development (pp. 128-144). Hersey: IGI Global.

Karpicke, J. D., \& Roediger, H. L. (2008). The critical importance of retrieval for learning. Science, 319(5865), 966-968.

Lin, K. Y., Hong, H.-Y., \& Chai, C. S. (2014). Development and validation of the knowledge-building environment scale. Learning and Individual Differences, 30, 124 132.

Lipponen, L. (2010, April 15). Exploring foundations for computer-supported collaborative learning. In G. Stahl (Ed.), Computer support for collaborative learning: Foundations for a CSCL community: Proceedings of the copmuter-supported collaborative learning 2002 conference (pp.72-81). Hilsdale, NJ: Erlbaum.

Mascolo, M. F. (2009). Beyond student-centered and teacher-centered pedagogy: Teaching and learning as guided participation. Pedagogy and the Human Sciences, 1(1), $3-27$.

Mayer, R. E., \& Alexander, P. A. (2011). Handbook of research on learning and instruction. Routledge.

Rodgers, C. (2002). Defining reflection: Another look at John Dewey and reflective thinking. Teachers College Record, 104(4), 842-866.

Scallon, G. (2007). L'évaluation des apprentissages dans une approche par compétences. Revue des Sciences de L'éducation, 32(3), 815-816. 
Scardamalia, M., \& Bereiter, C. (2006). Knowledge building: Theory, pedagogy, and technology. In K. R. Sawyer (Ed.), Cambridge handbook of the learning sciences (pp. 97-118). Cambridge University Press.

Shadish, W. R., Cook, T. D., \& Campbell, D. T. (2002). Experimental and quasiexperimental designs for generalized causal inference. Boston, MA: Houghton, Mifflin and Company.

Stahl, G., Koschmann, T., \& Suthers, D. (2006). Computer-supported collaborative learning: An historical perspective. In R. k. Sawyer (Ed.), Cambridge handbook of the learning sciences (pp. 409-426). Cambridge, UK: Cambridge University Press

Wu, Y. T. (2013). University students' knowledge structures and informal reasoning on the use of genetically modified foods: Multidimensional analyses. Res Sci Educ, 43, 1873-1890

Wu, Y. T., \& Tsai, C. C. (2007). High School students' informal reasoning on a socioscientific issue: Qualitative and quantitative analyses. International Journal of Science Education, 29(9), 1163-1187

Wu, Y. T., \& Tsai, C. C. (2011). The effects of different on-line searching activities on high school students' cognitive structures and informal reasoning regarding a socioscientific issue. Res Sci Educ, 41, 771-785

Yücel, Ü. A., \& Usluel, Y. K. (2016). Knowledge building and the quantity, content and quality of the interaction and participation of students in an online collaborative learning environment. Computers \& Education, 97, 31-48. 